\title{
Cytokine concentrations direct endothelial function in pregnancy and preeclampsia
}

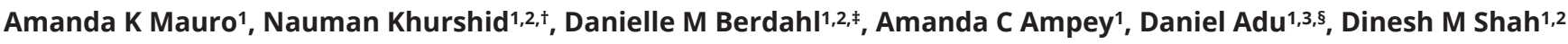 \\ and Derek S Boeldt ${ }^{1}$ \\ ${ }^{1}$ Perinatal Research Laboratories, Department of Obstetrics \& Gynecology, University of Wisconsin - Madison, School Medicine and Public Health, Madison, \\ Wisconsin, USA \\ 2Division of Maternal Fetal Medicine, Department of Obstetrics \& Gynecology, University of Wisconsin - Madison, School Medicine and Public Health, \\ Madison, Wisconsin, USA \\ 3Department of Pediatrics, University of Wisconsin - Madison, School Medicine and Public Health, Madison, Wisconsin, USA
}

Correspondence should be addressed to D S Boeldt: dsboeldt@wisc.edu

†(N Khurshid is now at Promedica Toledo Hospital, Toledo, Ohio, USA)

${ }^{\ddagger}(\mathrm{D}$ M Berdahl is now at Parkview Health, Fort Wayne, Indiana, USA)

$\S$ (D Adu is now at Geisinger Medical Center, Danville, Pennsylvania, USA)

\begin{abstract}
Endothelial dysfunction is a prominent feature of preeclampsia, a hypertensive disorder of pregnancy, and contributes to multiple symptoms characteristic of the syndrome. A myriad of growth factors and cytokines are dysregulated in preeclampsia as compared to normal pregnancy, however, a complete appreciation of the effect of changing concentrations of these factors on endothelial function is lacking. In this study, we evaluate the effect of a variety of growth factors and cytokines on $\mathrm{Ca}^{2+}$ signaling and monolayer integrity. We report that VEGF $165, \mathrm{TNF} \alpha, \mathrm{EGF}$, and IL-1 $\beta$ either improve or inhibit $\mathrm{Ca}^{2+}$ signaling depending on dose, whereas TNF $\alpha$ and IL-1 $\beta$ reduce monolayer integrity and bFGF increases monolayer integrity. Additionally, to model the effects of combinations of growth factors and cytokines, we screened for $\mathrm{Ca}^{2+}$ signaling changes in response to 16 dose combinations of $\mathrm{VEGF}_{165}$ and TNF $\alpha$ together. This revealed an optimal combination capable of supporting pregnancy-adapted $\mathrm{Ca}^{2+}$ signaling, and that changes in either VEGF 165 or TNF $\alpha$ dose would result in a shift toward suppressed function. This study shows in detail how growth factor or cytokine concentration effects endothelial cell function. Such data can be used to model how changing growth factor and cytokine levels in normal pregnancy may contribute to healthy endothelial function and in preeclampsia may promote endothelial dysfunction. The results of $\mathrm{VEGF}_{165}$ and TNF $\alpha$ combination treatments suggest that more complex growth factor and cytokine combination modeling may be important in order to more accurately understand the effects of circulating factors on the endothelial function.
\end{abstract}

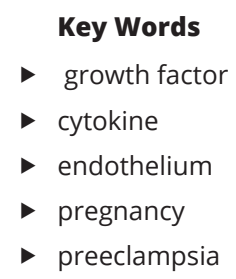

Journal of Endocrinology (2021) 248, 107-117

\section{Introduction}

Preeclampsia (PE) is a hypertensive disorder of pregnancy that occurs in $5-8 \%$ of all pregnancies. Significant morbidities can occur to the mother and fetus, and in extreme cases, death can result. Mothers who develop
PE and babies born of PE pregnancies are at higher risk of developing cardiovascular disorders later in life. The etiology of PE is incompletely understood, but endothelial dysfunction is a central component to a number of the 
symptoms used in diagnosis of the disorder (hypertension, proteinuria, cerebral edema) (Hammer \& Cipolla 2015, Pauli \& Repke 2015). Our poor understanding of the mechanisms of vascular adaptations to pregnancy makes it difficult to pinpoint mechanisms of failure or suppression of pregnancy adapted function. However, endothelial vasodilator production has been extensively studied as a potentially critical component of pregnancy adaptation and PE-mediated endothelial dysfunction (Sladek et al. 1997, Osol et al. 2017).

Pregnancy-adapted endothelial function has been firmly established as responsible for the increased connexin 43 (Cx43) gap junction connectivity and communication between endothelial cells that is necessary to support the demands of pregnancy and placentation on maternal vasculature (Yi et al. 2010, Morschauser et al. 2014). The pregnancy-adapted state is dependent on the maintenance of cell-cell connections and manifests in coordinated and sustained $\mathrm{Ca}^{2+}$ signaling that stimulates increased nitric oxide (NO) production. In pregnancy, there are changes in levels of many growth factors and cytokines as compared to the non-pregnant state, and further changes occur in PE compared to normal pregnancies. Stimulation of kinase signaling cascades and transcriptional regulation as a consequence of changing growth factor and cytokine concentrations is, therefore, a prime candidate for promoting endothelial dysfunction, likely through interfering with these cell-cell connections that are so critical to pregnancy-adapted endothelial function (Boeldt et al. 2015, Ampey et al. 2019, Mauro et al. 2020).

In this study, we seek to screen the effects of growth factors $\left(\mathrm{VEGF}_{165}, \mathrm{PlGF}, \mathrm{EGF}, \mathrm{bFGF}\right)$ and cytokines (TNF $\alpha$, IL-6, IL-8, IL-1 $\beta$ ) commonly reported to differ in normal pregnancies as compared to PE pregnancies (Hohlagschwandtner et al. 2002, Zhang et al. 2003, Szarka et al. 2010, Dong \& Yin 2014, Armant et al. 2015, Boeldt \& Bird 2017, Nejabati et al. 2017) for their dose-dependent effects on $\mathrm{Ca}^{2+}$ signaling and monolayer integrity in human umbilical vein endothelial cells (HUVEC), two important determinants of endothelial function. Furthermore, we present our findings on modeling combinations (16 combination doses) of $\mathrm{VEGF}_{165}$ and TNF $\alpha$ using highthroughput methodology to reveal what changes in endothelial cell signaling function may occur at the uteroplacental interface (where both may be elevated) or in systemic vasculature of the mother where free $\mathrm{VEGF}_{165}$ is very low in PE subjects. The results of this study lay the foundation of the effect of growth factor or cytokine dose on endothelial function. The application of this knowledge extends not only to PE but naturally to other diseases involving inflammation and endothelial dysfunction.

\section{Materials and methods}

\section{Materials}

Fura-2 AM and Pluronic F127 were obtained from Life Technologies, $\mathrm{CaCl}_{2}$ from EMD Millipore. ATP (disodium salt), heparin sodium salt and all other chemicals were purchased from Sigma-Aldrich unless otherwise stated. Minimum Essential Medium (MEM) and fetal bovine serum (FBS) were from Invitrogen (Life Technologies Inc.). Endothelial Cell Growth Supplement (ECGS) was from Millipore. Krebs buffer $(125 \mathrm{mM} \mathrm{NaCl}, 5 \mathrm{mM} \mathrm{KCl}$, $1 \mathrm{mM} \mathrm{MgSO}_{4}, 1 \mathrm{mM} \mathrm{KH_{2 }} \mathrm{PO}_{4}, 6 \mathrm{mM}$ glucose, $25 \mathrm{mM}$ HEPES, $2 \mathrm{mM} \mathrm{CaCl}_{2}$, pH 7.4) was used as experimental buffer. HUVEC growth medium for $\left[\mathrm{Ca}^{2+}\right]_{\mathrm{i}}$ assay was $\mathrm{HEH}$ medium (Human, ECGS, Heparin) and is as described in Krupp et al. (2013). For the monolayer integrity assay the HUVEC growth medium was ECM and ECMb was used as the media for experimental treatment (ScienCell, Carlsbad, CA). bFGF, EGF, VEGF ${ }_{165}$, TNF $\alpha$, PlGF, IL-6, IL-8, and IL- $1 \beta$ were purchased from R\&D Systems.

\section{Human subjects enrollment and umbilical cord collection}

This study was approved by the institutional review boards of Meriter Hospital (Madison, WI) and the University of Wisconsin-Madison (Madison, WI). All subjects signed formal consent, and samples were de-identified prior to tissue collection. Human umbilical vein endothelial cells were immediately isolated and expanded for future use.

\section{Isolation of human umbilical vein endothelial cells}

HUVEC from normal pregnancies were collected and validated as in Krupp et al. (2013). Cells from individual patients were harvested from fresh umbilical cords immediately after delivery and maintained in culture to passage 2. Individual preps (5) were grown, pooled, and frozen as pools at passage 3 for experimental use. All experiments were undertaken on pooled cells.

\section{$\left[\mathrm{Ca}^{2+}\right]_{\mathrm{i}}$ plate reader assay}

Pooled passage 3 HUVEC were plated and grown in 48 wells of 96-well clear bottom black plates (Corning Technologies). After $\sim 4$ days, when cells reached $>90 \%$ confluence, cells were loaded with Fura-2 AM just as in 
the imaging protocol previously. After loading and ester hydrolysis cells were pretreated with $\mathrm{VEGF}_{165}$, EGF, bFGF, PlGF, IL-6, IL-8, IL-1 $\beta$ (30 min), or TNF $\alpha$ (60 min) at doses of $0.1,0.3,1,3,10,30$, and $100 \mathrm{ng} / \mathrm{mL}$. After pretreatment, 96-well plates were placed on the fluorescent plate reader (Biotek Synergy 2). Wells were exposed at and fluorescence emission detected at $510 \mathrm{~nm}$. Seven baseline reads were taken before auto-injection of ATP solution in Krebs buffer (final concentration $200 \mu \mathrm{M}$ ). Additional reads were taken roughly every $25 \mathrm{~s}$ for $15 \mathrm{~min}$. This protocol reflects what was used for growth factors and cytokines except for PlGF, for which the Biotek Cytation 5 system was used. This change occurred as the Synergy 2 was phased out and the Cytation 5 was acquired. Because of differences spectral properties in the Cytation 5, the wavelengths used for PlGF runs were 485 and $528 \mathrm{~nm}$ and Fluo8-AM dye was used. Mean baseline is calculated for each well from the seven pre-stimulation reads and is subtracted from all subsequent read intensities. $\mathrm{F} / \mathrm{F}_{0}$ is then calculated for each well before a mean for eight experimental wells per treatment per plate. A total of four plates are included in each data set.

\section{Monolayer integrity assay}

Pooled passage 3 HUVEC were plated on gelatin coated 96-well gold electrode plates and grown to confluence (48 h) on the electric cell-substrate impedance sensing (ECIS) system (Applied BioPhysics, Troy, NY) where resistance measurements were recorded to assess monolayer integrity. Once confluence was achieved, serum was withdrawn and cells were given $3 \mathrm{~h}$ to recover before treatment with a dose-response $(0.1,1,10 \mathrm{ng} / \mathrm{mL})$ of $\mathrm{VEGF}_{165}$, EGF, bFGF, PlGF, IL-6, IL-8, IL-1 $\beta$ or TNF $\alpha$. After treatment, resistance measurements continued to be recorded for $24 \mathrm{~h}$. Data were grouped by treatment and normalized to themselves using the timepoint $\sim 20$ min before treatment addition, where resistance was returned to pre-serum withdrawal levels and was stabilized, and then normalized to control. A total of at least four plates made up the data set with treatments run in triplicate.

\section{Statistical analysis}

Data for $\left[\mathrm{Ca}^{2+}\right]_{\mathrm{i}}$ are presented as both $\mathrm{F} / \mathrm{F}_{0}$ and $\mathrm{dF} / \mathrm{F}_{0}$ and statistical analysis was conducted by Student's $t$-test for individual factors and one-way ANOVA for the combinations. Data for monolayer integrity are presented as resistance normalized to control and statistical analysis was done by Student's $t$-test. For all analyses a value of $P<0.05$ was considered statistically significant.

\section{Results}

Because the concentration of circulating factors changes depending on normal and abnormal pregnancy as well as individual variance and tissue/vascular bed, we utilized a high-throughput plate reader $\mathrm{Ca}^{2+}$ response assay to determine dose-responses for the effects of growth factors (VEGF ${ }_{165}$, PlGF, EGF, and bFGF) and cytokines (TNF $\alpha$, IL-6, IL-8 and IL-1 $\beta$ ) on endothelial cell function across the entire physiologic range and beyond. Both stages of the $\mathrm{Ca}^{2+}$ response are important for NO production (Yi et al. 2011). The initial peak liberates endothelial nitric oxide synthase (eNOS) from the caveolae, while the sustained phase promotes eNOS activation, and is dependent on functional $\mathrm{Cx} 43$ plaques. In Fig. 1, we report total raw data, as well as quantification divided into initial peak and sustained phase responses for doses of $0,0.1,0.3,1,3,10$, 30 , or $100 \mathrm{ng} / \mathrm{mL}$ for each growth factor. Initial peak ATPstimulated $\mathrm{Ca}^{2+}$ responses were reduced by $3,10,30$, and $100 \mathrm{ng} / \mathrm{mL} \mathrm{VEGF}_{165}$ pretreatment, but were unchanged by PIGF, bFGF, or EGF at any concentration. We observed significant changes in sustained phase responses (mean of 6-8 $\mathrm{min}$, corresponding to the typical time of response plateau) for all factors tested at certain doses. Biphasic responses were observed for $\mathrm{VEGF}_{165}$, PlGF, and EGF. For $\mathrm{VEGF}_{165}$, the $1 \mathrm{ng} / \mathrm{mL}$ dose potentiated sustained phase ATP-stimulated $\mathrm{Ca}^{2+}$ responses, while 0.1, 0.3, 3, 10, 30, and $100 \mathrm{ng} / \mathrm{mL}$ significantly reduced sustained phase $\mathrm{Ca}^{2+}$. PlGF treatment improved the sustained phase response at 0.3 and $10 \mathrm{ng} / \mathrm{mL}$, while $3 \mathrm{ng} / \mathrm{mL}$ treatment trended toward an increased response but did not achieve statistical significance. With EGF pretreatment; 0.1 and 0.3 $\mathrm{ng} / \mathrm{mL}$ potentiated sustained phase $\mathrm{Ca}^{2+}$ responses, while 1 and $30 \mathrm{ng} / \mathrm{mL}$ doses achieved a significant reductions in ATP-stimulated sustained phase $\mathrm{Ca}^{2+}$. For bFGF, doses of 0.3 and $100 \mathrm{ng} / \mathrm{mL}$ achieved significant reduction in sustained phase $\mathrm{Ca}^{2+}$ responses.

In Fig. 2, we report the equivalent data for cytokines. Initial peak ATP-stimulated $\mathrm{Ca}^{2+}$ responses were unchanged by TNF $\alpha$, IL-6, IL-8, or IL- $1 \beta$ at any concentration. Biphasic responses in the sustained phase were observed for TNF $\alpha$, with potentiated $\mathrm{Ca}^{2+}$ responses at $1 \mathrm{ng} / \mathrm{mL}$ and reduced responses at $0.3,3,10,30$, and $100 \mathrm{ng} / \mathrm{mL}$. IL-6 and IL-8 offered improvement in the sustained phase response at $0.1 \mathrm{ng} / \mathrm{mL}$, with all other doses offering no statistically https://joe.bioscientifica.com

https://doi.org/10.1530/JOE-20-0397 (c) 2021 Society for Endocrinology Published by Bioscientifica Ltd.
Printed in Great Britain 

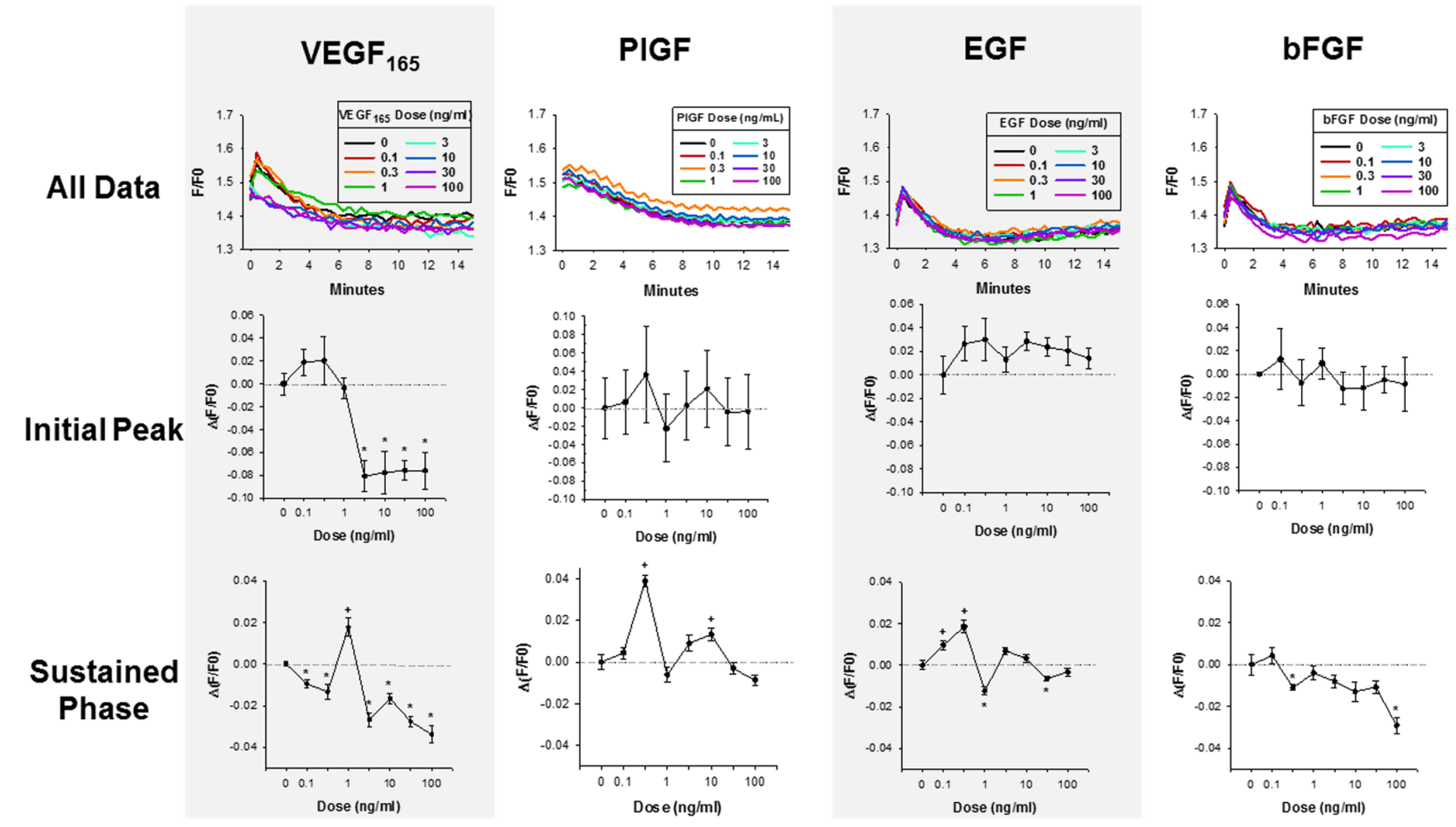

Figure 1

Growth factor dose-responses for initial peak and sustained phase ATP-stimulated $\mathrm{Ca}^{2+}$ responses. Fura-2 loaded HUVEC were pretreated with VEGF ${ }_{165}$, PIGF, bFGF, or EGF for 30 min at 0, 0.1, 0.3, 1, 3, 10, 30, or $100 \mathrm{ng} / \mathrm{mL}$ doses. Baseline $\mathrm{Ca}^{2+}$ was measured with total well fluorescence output at $340 \mathrm{~nm}$ excitation prior to $200 \mu \mathrm{M}$ ATP stimulation. The top row shows the dose-response as $F / F_{0}$ for each growth factor, with a fluorescence read approximately every $23 \mathrm{~s}$ for roughly $15 \mathrm{~min}$. The middle row quantifies the change in fluorescence compared to the $0 \mathrm{ng} / \mathrm{mL}$ growth factor or cytokine control at the 2nd read for each well, corresponding to the timing of the peak $\mathrm{Ca}^{2+}$ levels. The bottom row depicts the change in fluorescence compared to control as in the middle row, but represents the mean level for minutes $6-8$, where the fluorescence output plateaus (i.e. the sustained phase). Dose-responses were carried out in a single 96-well plate with six total wells for each dose, with $n=$ minimum four plates. Data are shown as mean \pm s.E., $+P<0.05$ potentiation, $\star P<0.05$ inhibition by Student's $t$-test.

significant changes. With IL-1 $\beta$ pretreatment, increased sustained phase responses were observed for 0.3 and $3 \mathrm{ng} / \mathrm{mL}$ doses and a decreased response was observed for the $30 \mathrm{ng} / \mathrm{mL}$ dose.

To assess the effect of growth factor and cytokine on another facet of the endothelial function we utilized the ECIS system to measure insults or improvements for endothelial monolayer integrity. In Fig. 3 we report the data for the effect of a dose-response $(0.1,1,10 \mathrm{ng} / \mathrm{mL})$ of VEGF $_{165}$, PlGF, bFGF, and EGF on monolayer integrity. For $\mathrm{VEGF}_{165}$ an increase in monolayer integrity was observed early on (hours 1.9-4.6) for the $10 \mathrm{ng} / \mathrm{mL}$ dose, while all other doses were unable to mount a significant change. PlGF treatment largely did not result in changes in monolayer integrity, except for brief moments of statistical significance from 11 to $12.5 \mathrm{~h}$ for the $0.1 \mathrm{ng} / \mathrm{mL}$ dose and from 2.6 to $4 \mathrm{~h}$ for the $10 \mathrm{ng} / \mathrm{mL}$ dose. Treatment with 0.1 or $1 \mathrm{ng} / \mathrm{mL}$ EGF did not result in significant changes in monolayer integrity, but the $10 \mathrm{ng} / \mathrm{mL}$ dose resulted in a statistically significant decline beginning around hour 3 and worsening with increased time. In the case of bFGF the $0.1 \mathrm{ng} / \mathrm{mL}$ dose did not offer changes in monolayer integrity, while the $1 \mathrm{ng} / \mathrm{mL}$ dose offered improvements beginning around $10 \mathrm{~h}$ and the $10 \mathrm{ng} / \mathrm{mL}$ dose resulted in almost immediate improvements in monolayer integrity that continued to increase with time.

In Fig. 4, we report the results of TNF $\alpha$, IL-6, IL-8, and IL-1 $\beta$ treatment on monolayer integrity in the same way as was presented for the growth factors. TNF $\alpha$ treatment resulted in a dose-dependent reduction in monolayer integrity. The $0.1 \mathrm{ng} / \mathrm{mL}$ dose did not result in any changes to the monolayer, while the $1 \mathrm{ng} / \mathrm{mL}$ dose led to a decrease in monolayer integrity beginning around hour 7 with recovery beginning around hour 18 . The 10 $\mathrm{ng} / \mathrm{mL}$ dose resulted in a significant decline in monolayer integrity beginning around hour 4 that was maintained 

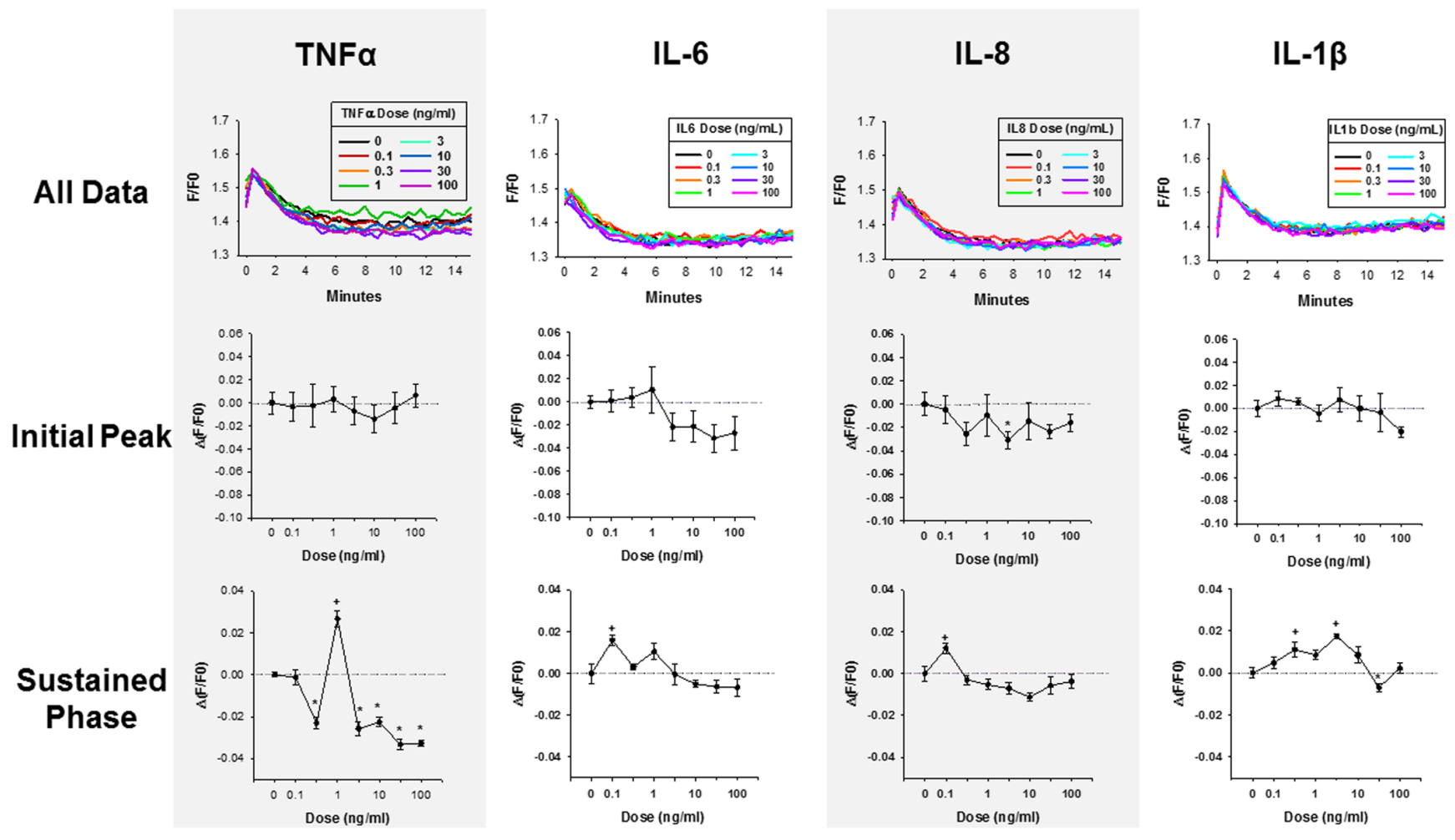

Figure 2

Cytokine dose-responses for initial peak and sustained phase ATP-stimulated $\mathrm{Ca}^{2+}$ responses. Fura-2 loaded HUVEC were pretreated with TNF $\alpha$ (60 min), IL-6, IL-8, or IL-1 $\beta$ for 30 min at 0, 0.1, $0.3,1,3,10,30$, or $100 \mathrm{ng} / \mathrm{mL}$ doses. Baseline $\mathrm{Ca}^{2+}$ was measured with total well fluorescence output at $340 \mathrm{~nm}$ excitation prior to $200 \mu \mathrm{M}$ ATP stimulation. The top row shows the dose-response as $\mathrm{F} / \mathrm{F}_{0}$ for each cytokine, with a fluorescence read approximately every $23 \mathrm{~s}$ for roughly $15 \mathrm{~min}$. The middle row quantifies the change in fluorescence compared to the $0 \mathrm{ng} / \mathrm{mL}$ growth factor or cytokine control at the 2nd read for each well, corresponding to the timing of the peak Ca2+ levels. The bottom row depicts the change in fluorescence compared to control as in the middle row, but represents the mean level for minutes $6-8$, where the fluorescence output plateaus (i.e. the sustained phase). Dose-responses were carried out in a single 96-well plate with six total wells for each dose, with $n=$ minimum four plates. Data are shown as mean \pm S.E., ${ }^{+} P<0.05$ potentiation, $\star P<0.05$ inhibition by Student's $t$-test.

through the entirety of the experiment. For both IL-6 and IL-8, there were no differences between treatment with any dose and control. Treatment with IL-1 $\beta$ also resulted in a dose-dependent reduction in monolayer integrity. The $0.1 \mathrm{ng} / \mathrm{mL}$ dose led to a reduction in monolayer integrity between hours 11 and 16, the $1 \mathrm{ng} / \mathrm{mL}$ dose led to a decrease beginning around hour 6 and extending throughout the experiment, and the $10 \mathrm{ng} / \mathrm{mL}$ dose leading to a sharp decline around hour 3 with a reduction in monolayer integrity continuing throughout the experiment.

In Fig. 5, we use treatments of $\mathrm{VEGF}_{165}$ and TNF $\alpha$ at doses of $0,0.1,1$, and $10 \mathrm{ng} / \mathrm{mL}$ in 16 total combinations to assess signaling addition, synergy, or interference which may potentiate or inhibit ATP-stimulated $\mathrm{Ca}^{2+}$ signaling. The left panel depicts a contour plot of the effect of VEGF $_{165}$ and TNF $\alpha$ combination treatments on initial peak ATP-stimulated $\mathrm{Ca}^{2+}$ signaling, with warm colors (light blue, green, orange, yellow) indicating response potentiation (pro vasodilatory response) and cool colors (dark blue, purple) indicating response inhibition (pro vasoconstriction). A clear zone corresponding to optimal levels of $\mathrm{VEGF}_{165}$ and TNF $\alpha$ is observed, centered around a response potentiation peak at $1 \mathrm{ng} / \mathrm{mL} \mathrm{VEGF}_{165}$ and 0.1 $\mathrm{ng} / \mathrm{mL}$ TNF $\alpha$. Regardless of TNF $\alpha$ dose, $10 \mathrm{ng} / \mathrm{mL}$ VEGF 165 inhibits initial peak height. The center panel shows a 3-D view of the contour plot for VEGF $_{165}$ and TNFo combination effects on sustained phase ATP-stimulated $\mathrm{Ca}^{2+}$ responses. The right panel shows the same sustained phase data as an overhead view of the contour plot, with the same conditions as the initial peak data in the left panel. Once again, a clear optimal response potentiation zone centers around the $1 \mathrm{ng} / \mathrm{mL} \mathrm{VEGF}_{165}$ and $0.1 \mathrm{ng} / \mathrm{mL}$ TNF $\alpha$ dose combination. However, during the sustained phase, the protective effect of either $1 \mathrm{ng} / \mathrm{mL}$ VEGF $_{165}$ or $1 \mathrm{ng} / \mathrm{mL}$ TNF $\alpha$ becomes apparent, as indicated by the 


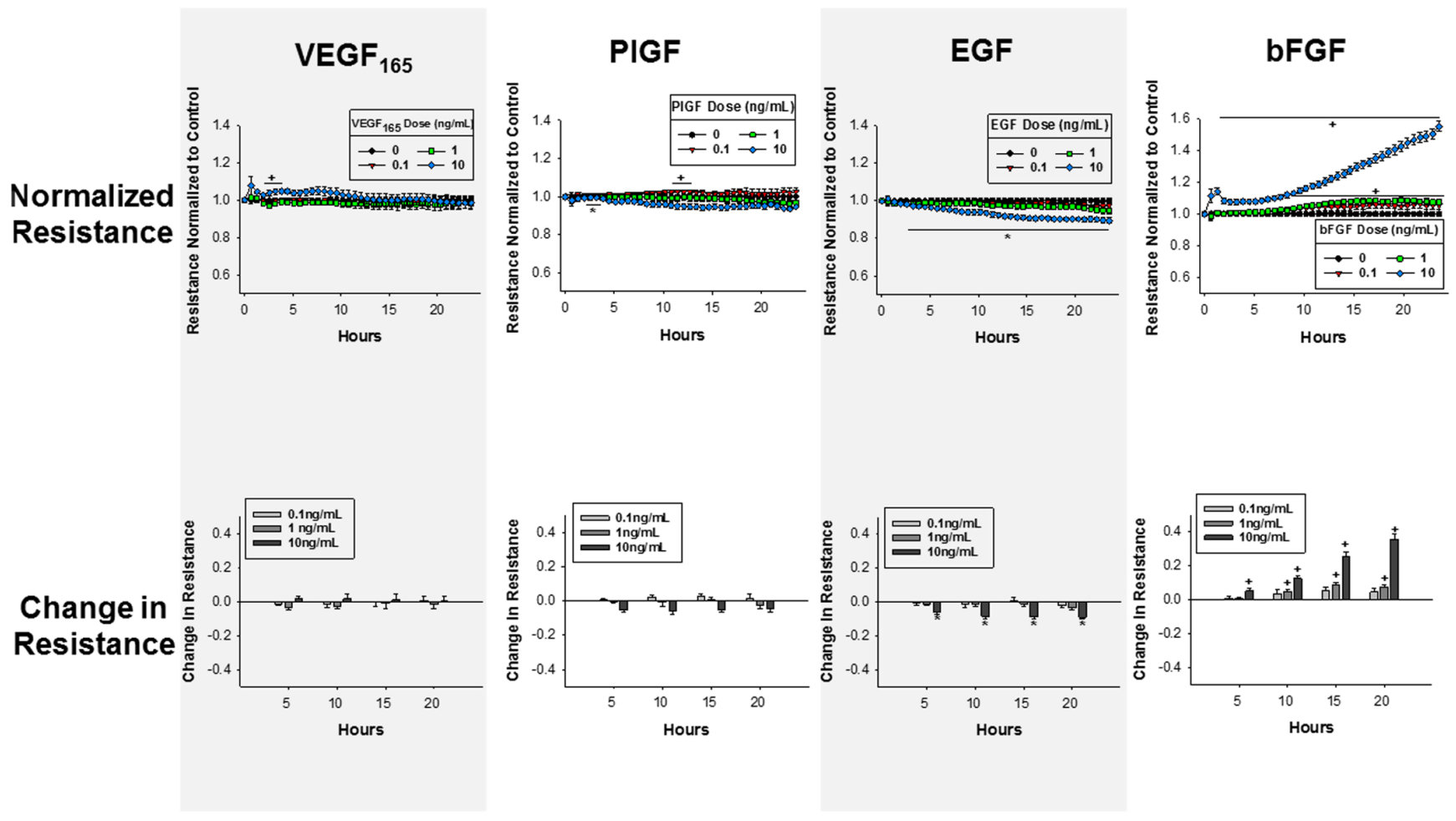

\section{Figure 3}

Growth factor dose-responses for impact on monolayer integrity. HUVEC grown to confluence on 96-well gold electrode plates were treated with $\mathrm{VEGF}_{165}, \mathrm{PIGF}, \mathrm{EGF}$, or bFGF at $0.1,1$, and $10 \mathrm{ng} / \mathrm{mL}$ for assessment of monolayer integrity via resistance measurements. Data points were collected for 24 $\mathrm{h}$ after the addition of growth factors. The top row shows the dose-responses as resistance normalized to control from growth factor treatment to experiment completion. The bottom row shows the change in resistance compared to control for isolated time points every $5 \mathrm{~h}$ within the experiment. A total of six 96 -well plates were used with each dose run in triplicate within each plate. Data are shown as mean \pm s.E., ${ }^{+} P<0.05$ potentiation $* P<0.05$ inhibition by Student's $t$-test.

green (slightly potentiating) swaths corresponding to those doses. As with the initial peak, $10 \mathrm{ng} / \mathrm{mL} \mathrm{VEGF}_{165}$ is the strongest indicator of sustained phase response inhibition. Data for Fig. 5 are shown in Table 1 along with $P$ values indicated by symbols.

\section{Discussion}

As stated in the 'Introduction' section, numerous studies have implicated circulating factors in the pathogenesis of PE, although considerable debate still exists about which factors are most responsible. While it has proven impossible to link such symptoms to a single circulating factor, our data show that, of the growth factors and cytokines surveyed here, $\mathrm{VEGF}_{165}$ and TNF $\alpha$ were the most detrimental to $\mathrm{Ca}^{2+}$ signaling and TNF $\alpha$ and IL- $1 \beta$ to monolayer integrity with dose as an important determinant of inhibition in all cases. Further analysis using $\mathrm{VEGF}_{165}$ and TNF $\alpha$ combinations revealed an optimal peak for support of $\mathrm{Ca}^{2+}$ signaling function.
All the above findings highlight conditions supporting pregnancy-adapted endothelial function vs conditions characteristic of and potentially further contributing to endothelial dysfunction in PE.

Because the initial phase of the $\mathrm{Ca}^{2+}$ response is crucial in permitting $\mathrm{NO}$ production it is important to consider changes to both initial and sustained phases in response to growth factor or cytokine treatment. Few factors in this study significantly changed the initial phase response, confirming previous assertions that a greater focus on sustained phase $\mathrm{Ca}^{2+}$ responses is warranted. The two factors to result in statistically significant changes to the initial phase response were $\mathrm{VEGF}_{165}$ (at doses $3 \mathrm{ng} / \mathrm{mL}$ and above) and IL-8 (at $3 \mathrm{ng} / \mathrm{mL}$ only). As has been stated elsewhere (Yi et al. 2011, Boeldt et al. 2017) and demonstrated here, VEGF $_{165}$ can have positive or negative effects on endothelial cell function depending on the physiological context of VEGF $_{165}$ exposure and dose experienced. This concept is on display here in both the results for the initial phase and the sustained phase $\mathrm{Ca}^{2+}$ response. The result that one dose of IL-8 negatively 

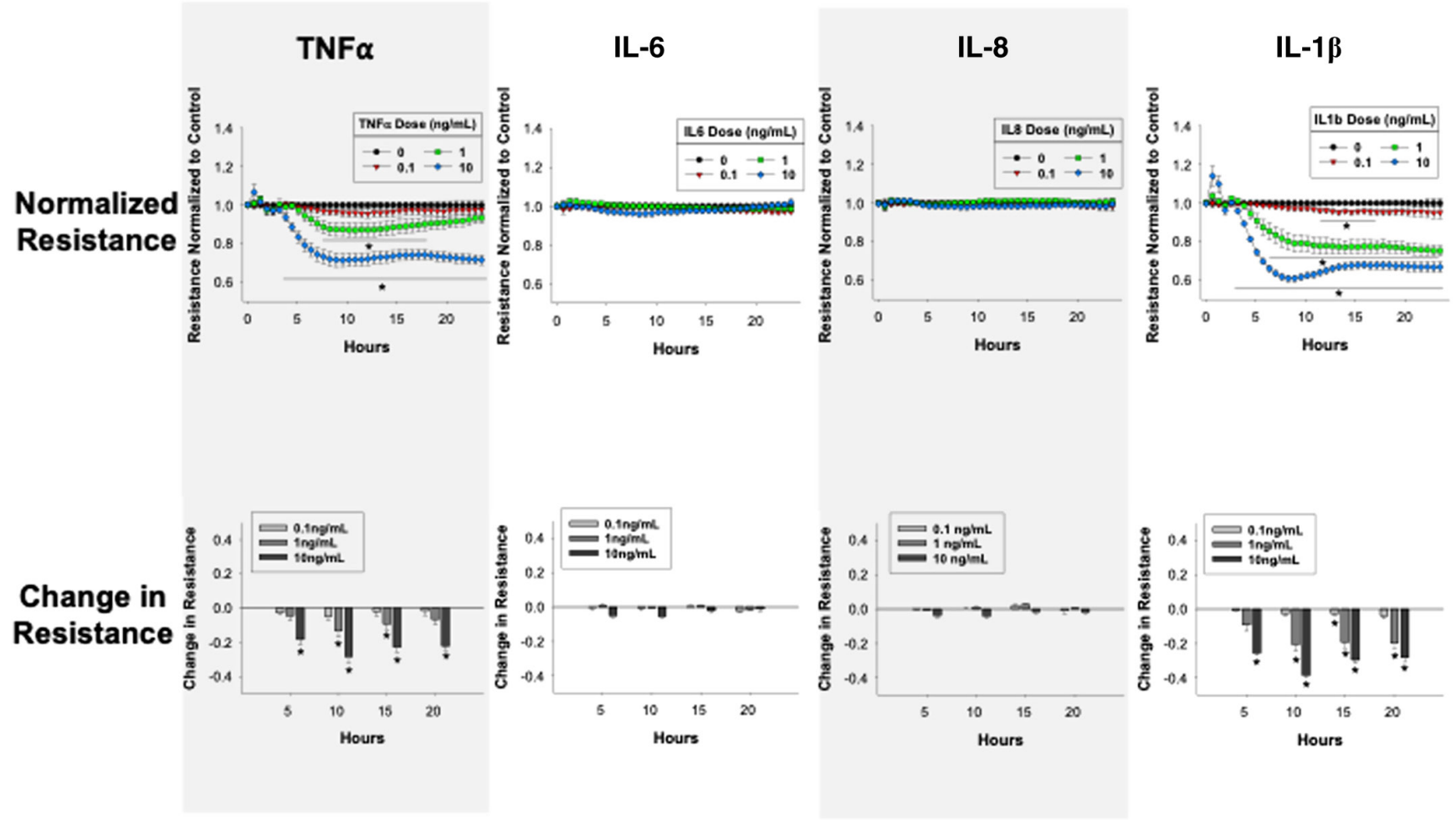

\section{Figure 4}

Cytokine dose-responses for impact on monolayer integrity. HUVEC grown to confluence on 96-well gold electrode plates were treated with TNF $\alpha$, IL-6, $\mathrm{IL}-8$, or IL-1 $\beta$ at $0.1,1$, and $10 \mathrm{ng} / \mathrm{mL}$ for assessment of monolayer integrity via resistance measurements. Data points were collected for $24 \mathrm{~h}$ after the addition of cytokines. The top row shows the dose-responses as resistance normalized to control from growth factor treatment to experiment completion. The bottom row shows the change in resistance compared to control for isolated time points every $5 \mathrm{~h}$ within the experiment. A total of six 96-well plates were used with each dose run in triplicate within each plate. Data are shown as mean \pm S.E., ${ }^{*} P<0.05$ potentiation, $* P<0.05$ inhibition by Student's $t$-test.

impacted the initial phase $\mathrm{Ca}^{2+}$ response is interesting given that in this study and in previous work (Mauro et al. 2020) IL-8 has been shown to not significantly alter the $\mathrm{Ca}^{2+}$ response in HUVECs otherwise. The reduction in the initial phase response caused by $3 \mathrm{ng} / \mathrm{mL}$ IL- 8 is relatively modest and likely does not result in a physiologically meaningful reduction in NO production. The reduction in the initial phase response for the higher doses of $\mathrm{VEGF}_{165}$ is of much greater magnitude and is likely capable of causing a corresponding reduction in NO production. In both ovine uterine arteries and human umbilical veins, it has been shown that $10 \mathrm{ng} / \mathrm{mL} \mathrm{VEGF}{ }_{165}$ treatment led to a reduction in NO production (Yi et al. 2011, Boeldt et al. 2015). As the other inhibitory $\mathrm{VEGF}_{165}$ doses in the current study were just as inhibitory as the $10 \mathrm{ng} / \mathrm{mL}$ dose it is likely that those doses mirror the reduction in NO production mediated by the $10 \mathrm{ng} / \mathrm{mL}$ dose.

With respect to the sustained phase $\mathrm{Ca}^{2+}$ response, we have previously established that $\mathrm{Cx} 43$ function is a key component to pregnancy-adapted enhancement of the sustained phase $\mathrm{Ca}^{2+}$ response (Krupp et al. 2013, Boeldt et al. 2014b, Morschauser et al. 2014). Furthermore, we have reported in intact uterine vessels and umbilical veins that $\mathrm{VEGF}_{165}$ is a known promoter of vasodilator production (Yi et al. 2010, 2011, Boeldt et al. 2014a), so it is noteworthy that the $1 \mathrm{ng} / \mathrm{mL}$ dose potentiated ATPstimulated sustained phase $\mathrm{Ca}^{2+}$ responses. However, when the dose of $\mathrm{VEGF}_{165}$ falls to $0.3 \mathrm{ng} / \mathrm{mL}$ or rises to 3 $\mathrm{ng} / \mathrm{mL}$, the beneficial effect is lost and instead becomes inhibitory. This narrow range of beneficial doses could help explain much of the controversy over the role the soluble $\mathrm{VEGF}_{165}$ receptor sFlt- 1 in $\mathrm{PE}$, and why treatments designed to modulate $\mathrm{VEGF}_{165}$ bioavailability are extremely difficult to design. It is not simply a matter of removing $\mathrm{VEGF}_{165}$ because it is 'bad' or increasing $\mathrm{VEGF}_{165}$ because it is 'good'. A slight deviation on either side of the optimal $\mathrm{VEGF}_{165}$ levels results in a poor consequence. While the reason for this is unclear, it is reasonable that the endothelium would have reserve capacity to acutely increase vasodilation and blood flow in response to minor insults (e.g. transient hypoxia), while quickly reducing vasodilator output and decrease blood flow in the event 
Initial Peak

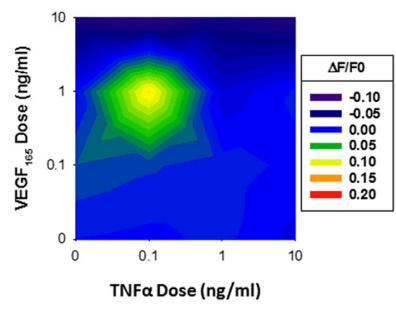

Sustained Phase 3D

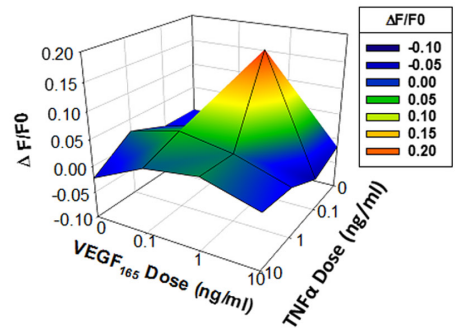

Sustained Phase

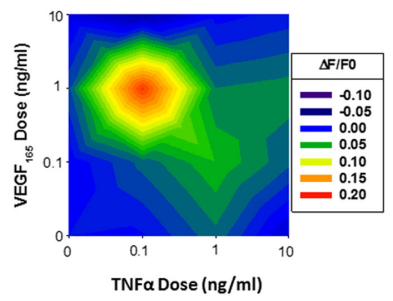

\section{Figure 5}

VEGF $_{165}$ and TNF $\alpha$ combinations produce an 'optimal zone' of enhanced ATP-stimulated Ca ${ }^{2+}$ function. HUVEC were pretreated with a combination of VEGF $_{165}$ and TNF $\alpha$ for $30 \mathrm{~min}$ at $0,0.1,1$, and $10 \mathrm{ng} / \mathrm{mL}$ doses for a total of 16 combinations, prior to ATP stimulation. Baseline Ca ${ }^{2+}$ was measured for 3 min after Fura-2 loading, measuring total well fluorescence output at $340 \mathrm{~nm}$ excitation. Cells were then stimulated with $200 \mu \mathrm{M}$ ATP for roughly 15 additional minutes, with fluorescence recording occurring approximately every $23 \mathrm{~s}$. The left panel shows an overhead view (contour plot) of $\Delta F / F_{0}$ for the initial $\mathrm{Ca}^{2+}$ peak, with light blue, greens, yellows, and reds depicting neutral or increase over control conditions and dark blues and purples depicting a decrease. The right panel is the same sustained phase plot from an overhead view. The green, yellow, and red colors pinpoint an 'optimal zone' where certain doses of $\mathrm{VEGF}_{165}$ and TNF $\alpha$ combine to produce an enhanced peak and sustained phase $\mathrm{Ca}^{2+}$ response. The middle panel shows the sustained phase $\triangle F / F 0$ as calculated in the right panel in a 3-D representation with the same color scheme. Statistics and data are shown in Table 1.

of a major insult. Certainly, this idea has been understood in the wound healing field (Bao et al. 2009, Kaplani et al. 2018) but has not been investigated in pregnancy adaptation and hypertensive disorders of pregnancy.

PlGF also plays a role in angiogenesis and vasodilation in pregnancy and is also subjected to sequestration by sFlt-1 (Umapathy et al. 2020). PlGF preferentially binds to VEGFR1 over VEGFR2, potentially, therefore, increasing VEGF $_{165}$ binding to VEGFR2 (Lecarpentier \& Tsatsaris 2016). At the 3 and $10 \mathrm{ng} / \mathrm{mL}$ doses for PlGF treatment, there were significant improvements in $\mathrm{Ca}^{2+}$ signaling, indicating that at these doses PlGF is the most supportive of endothelial function. These doses may relate more closely to levels found in the placenta in normal pregnancies, as reported in some studies that PlGF expression is decreased in PE placentas (Umapathy et al. 2020). This seems to mirror the 'optimal zone' argument for $\mathrm{VEGF}_{165}$ function, however, the lack of any significant inhibition of $\mathrm{Ca}^{2+}$ signaling of any dose of PlGF prevents the theory from extending to PlGF as well. The impact of changes in PlGF levels in pregnancy and PE may be more related to its impact on the ability of $\mathrm{VEGF}_{165}$ to remain in its optimal zone of bioavailability and action than its direct action on the endothelium.

Changes in circulating levels of EGF or bFGF are not strongly linked with the incidence of PE, but both growth factors are known to activate Src kinase pathways. The amplitude of sustained $\mathrm{Ca}^{2+}$ responses in the presence of EGF indicates that EGF may be a more important positive influence on endothelial cell function at low doses than it is an inhibitor at higher doses. This is likely due to the fact that few EGF receptors are present on the surface of HUVEC, negating the extent to which signaling cascades, such as Src family kinases, are activated. That bFGF does not promote sustained $\mathrm{Ca}^{2+}$ responses at any dose is curious and could be worthy of further investigation, however, bFGF treatment did result in a reduction in $\mathrm{Ca}^{2+}$ bursting response in previous studies (Mauro et al. 2020), and may be a consequence of differences in methodologies utilized.

TNF $\alpha$ displayed a nearly identical dose-response curve to that of $\mathrm{VEGF}_{165}$ for sustained phase $\mathrm{Ca}^{2+}$, including again

Table 1 Data for VEGF 165 and TNF combinations for $\mathrm{Ca}^{2+}$ signaling.

\begin{tabular}{|c|c|c|c|c|c|c|c|c|}
\hline \multirow{2}{*}{$\frac{\text { VEGF dose } \downarrow}{0}$} & \multicolumn{8}{|c|}{ Initial phase $\Delta F / F_{0} \mid$ Sustained phase $\Delta F / F_{0}$} \\
\hline & $0^{a}$ & $0^{b}$ & $-0.003^{a}$ & $-0.001 b$ & $0.003^{a}$ & $0.027 * * *, b$ & $-0.014^{*, a}$ & $-0.023^{b}$ \\
\hline 0.1 & $0.019^{a}$ & $-0.010 * \star \star, b$ & $0.012^{\mathrm{a}}$ & $0.023^{b}$ & $0.004^{a}$ & $0.049 *, b$ & $-0.002^{a}$ & $0.022^{b}$ \\
\hline 1 & $-0.004^{a}$ & $0.018^{\mathrm{b}}$ & $0.112^{a}$ & $0.1833 * * *, b$ & $-0.018^{a}$ & $0.030^{b}$ & $0.002^{a}$ & $0.035^{b}$ \\
\hline 10 & $-0.077 *, a$ & $-0.016 * *, b$ & $-0.091 * *, a$ & $-0.038 * * *, b$ & $-0.069 *, a$ & $-0.005^{* * *, b}$ & $-0.079 *, a$ & $0.004 * * *, b$ \\
\hline TNF $\alpha$ dose $\rightarrow$ & & 0 & & 0.1 & & 1 & & 10 \\
\hline
\end{tabular}

The data in this table display the $D F / F_{0}$ values for each VEGF 165 and TNF $\alpha$ combinations, with VEGF 165 doses $(\mathrm{ng} / \mathrm{mL}$ ) on the left and TNF $\alpha$ doses (ng/mL) on the bottom. aData for the initial phase; 'Data for the sustained phase. Negative values indicate inhibition compared to control, whereas positive values indicate potentiation compared to control. Statistics were done by one-way ANOVA and Student's t-test, $* \star \star * P<0.001, * \star P<0.01, * P<0.05$. 
a single dose potentiated ATP-stimulated $\mathrm{Ca}^{2+}$ response. This was surprising since we have previously shown that in HUVECs and UAECs that TNF $\alpha$ reduces individual $\mathrm{Ca}^{2+}$ bursts (Ampey et al. 2019, Mauro et al. 2020). Indeed, the vast majority of studies report a link between TNF $\alpha$ and endothelial dysfunction or immune responses. In PE there is a shift toward a pro-inflammatory state, indicated as a shift toward a Th1 immune profile (Rambaldi et al. 2019). It should be noted, however, that most functional studies utilize concentrations far greater than $1 \mathrm{ng} / \mathrm{mL}$ and typically seek to tie endothelial dysfunction to oxidative stress (Ampey et al. 2019). Our data suggesting a beneficial effect at $1 \mathrm{ng} / \mathrm{mL}$ is relevant since normal healthy pregnancies are a state of mild inflammation and yet $\mathrm{TNF} \alpha$ concentrations in normal pregnancy rarely reach 1 ng/mL (Xie et al. 2011, Lau et al. 2013), although it may be approached in the circulation in PE subjects and exceeded at the uteroplacental interface. Such increased endothelial function through the $1 \mathrm{ng} / \mathrm{mL}$ range may implicate an endothelial cell reserve for increased vasodilation in cases of mild infection, hypoxia or other transient forms of immune stimulation that are not considered dangerous (such as mild illness). Within tissues where excess TNFo is produced, the positive effects of TNF $\alpha$ are only limited to a narrow dose range, so local excess production of TNF $\alpha$ would surely expose the endothelium to higher levels than $1 \mathrm{ng} / \mathrm{mL}$, and further increases could be very damaging.

Like TNF $\alpha$, the interleukins were unable to mount a significant change in the ability of cells to mount an initial $\mathrm{Ca}^{2+}$ response peak in response to ATP. Interestingly, IL-6 was able to offer some improvements in the sustained phase $\mathrm{Ca}^{2+}$ response. Increased IL-6 expression has been implicated in increased incidence of fetal growth restriction (Street et al. 2006), and we have previously reported that IL-6 treatment results in a modest but significant decrease in individual $\mathrm{Ca}^{2+}$ bursts (Mauro et al. 2020). Similar observations occurred for IL-8, where we have previously shown decreased $\mathrm{Ca}^{2+}$ bursting after treatment (Mauro et al. 2020) but saw either no changes or improvement in the sustained phase response reported here. The effect of IL- $1 \beta$ on $\mathrm{Ca}^{2+}$ was essentially the same story as the previous interleukins; no change in the initial peak, but some increases in the sustained phase. However, IL- $1 \beta$ did produce a modest reduction in sustained phase signaling at the $30 \mathrm{ng} / \mathrm{mL}$ dose, but this supraphysiological dose is unlikely to occur in normal pregnancy or PE (Montagnana et al. 2008).

VEGF $_{165}$ has been shown to have a biphasic effect on monolayer permeability, initially increasing permeability in the short term but offering monolayer stabilization in the long term (Gao et al. 2017). Contradictory to this, here we observe initially a very brief period of statistically significant but modest improvement seen with $10 \mathrm{ng} / \mathrm{mL}$ $\mathrm{VEGF}_{165}$ treatment. The study cited for comparison (Gao et al. 2017) uses a $20 \mathrm{ng} / \mathrm{mL}$ dose of $\mathrm{VEGF}_{165}$, which could explain the difference in findings. This data indicates that $\mathrm{VEGF}_{165}$ in this case may be playing more of a role in monolayer maintenance and stabilization rather than altering connectivity or proliferation. The effect of PlGF treatment on monolayer integrity followed a similar trend. Out of all the growth factors examined here, the data for the effect of bFGF on monolayer integrity is the most striking. The physiologic implications for such a sharp increase in resistance is currently unclear and should be further investigated.

TNF $\alpha$ treatment negatively impacted monolayer integrity in a dose-dependent fashion. The $10 \mathrm{ng} / \mathrm{mL}$ dose led to reduced resistance that was sustained until experiment completion, whereas the impact of the $1 \mathrm{ng} / \mathrm{mL}$ was of lesser magnitude and resistance measurements recovered to control levels before completion of the experiment. This supports the notion that that dose could represent the endothelium's reserve capacity zone, where it can allow for increased immune cell passage and recruitment without resulting in sustained vascular leakiness. Treatment with IL-1 $\beta$ largely resembled the TNF $\alpha$ response, with the key differences being a further reduction in resistance with the $1 \mathrm{ng} / \mathrm{mL}$ dose that continued to be significantly below control through to the completion of the experiment. Both TNF $\alpha$ and IL-1 $\beta$ have been reported to have similar influences on endothelial protein levels in the context of inflammation including immune cell recruitment and oxidative stress (Beguin et al. 2019). Additionally, the effect of IL-6 and IL-8 were indistinguishable from control at any dose for the monolayer integrity assay. The true impact of IL-6 and/or IL-8 likely only can be realized when coupled with the action of another cytokine such as TNFa.

While evaluating individual growth factors and cytokines is a good start toward understanding their impact on endothelial cell function and how that can be applied to pregnancy and PE, it is likely that the combination of active signaling factors and the interactions of their downstream signaling cascades will be needed to accurately model and therapeutically target PE-related endothelial dysfunction. We began to address the effects of a combination of factors as compared to individual factors with $\mathrm{VEGF}_{165}$ and $\mathrm{TNF} \alpha$, finding that the positive effective dose of $\mathrm{TNF} \alpha$ on $\mathrm{Ca}^{2+}$ signaling is dependent on $\mathrm{VEGF}_{165}$ concentration. 
The positive or negative consequences of $\mathrm{VEGF}_{165}$ and TNF $\alpha$ bioavailability are clearly shown by the 3-D contour plot when applied to HUVEC in combination. A very narrow peak of optimal HUVEC $\mathrm{Ca}^{2+}$ function centers around $1 \mathrm{ng} / \mathrm{mL} \mathrm{VEGF}_{165}$ and $0.1 \mathrm{ng} / \mathrm{mL}$ TNF $\alpha$. Curiously, this centers around the $\mathrm{VEGF}_{165}$ alone peak, but not the TNF $\alpha$ alone peak. Because both $\mathrm{VEGF}_{165}$ and TNF $\alpha$ are known to phosphorylate $\mathrm{Cx} 43$ at Src-kinase-sensitive residues (Solan \& Lampe 2014, Boeldt et al. 2015, Ampey et al. 2019, Mauro et al. 2020), perhaps $1 \mathrm{ng} / \mathrm{mL}$ of each begins to overstimulate Src signaling pathways and precipitates inhibitory $\mathrm{Cx} 43$ phosphorylation. Further studies would be necessary to fully elucidate the positive/ negative switch. However, it should be noted that $1 \mathrm{ng} / \mathrm{mL}$ $\mathrm{VEGF}_{165}$ or $1 \mathrm{ng} / \mathrm{mL}$ TNF $\alpha$ can compensate to some degree for less than ideal concentrations of the other factor, as indicated by the extensions of green color on the contour plot. This could set up a system of checks and balances that could possibly compensate for one particular factor being out of the ideal range. However, the dose range for optimal endothelial function is still quite narrow. It appears that once growth factor and cytokine concentrations drift out of that range, even by a small amount, profound functional changes may occur, such that measures of small changes in circulating growth factors and cytokines in the blood may not easily or clearly indicate the overall effect on endothelial physiology.

\section{Conclusion}

In total, this study clearly shows that multiple growth factor and cytokine effects on endothelial cell function are exquisitely dependent on dose, and significant effects are clearly happening at doses far below the $10-50 \mathrm{ng} / \mathrm{mL}$ doses often used for in vitro studies. Also, within physiological ranges, these factors do not act alone and the presence of one may alter the effect of another. This is particularly relevant for two reasons. The first is it seems that a tightly regulated mix of many endocrine factors is necessary for optimal endothelial function in pregnancy if only to ensure inhibitory Src signaling common to many of them is not exceeded. It also may explain why measures of a single factor alone are not able to predict onset of PE or severity of disease, and yet there may still be a common signaling mediator of inhibition. Putting it simply, the action of one factor is not just dose-dependent on its own, it is clearly dependent on the presence of other co-stimulants. Two patients with the same TNF $\alpha$ level may show different symptoms precisely because the inhibitory action is altered by other factors that also signal through ERK and Src. Of note there are other factors in vivo that are not potent effectors of ERK or Src but may alter their site of action (such as interleukins working through GP 130). Future in vitro studies should therefore carefully consider growth factor or cytokine dose with respect to the applicability of any results to physiological outcomes in vivo. Perhaps as importantly, modeling complex endocrine signaling interactions and hierarchies will provide crucial insights into the possible mechanisms underlying endothelial dysfunction in pathophysiologic diseases including but not limited to PE.

\section{Declaration of interest}

The authors declare that there is no conflict of interest that could be perceived as prejudicing the impartiality of the research reported.

\section{Funding}

This work was funded by the National Institutes of Health grant award HD079865. This paper reports partial fulfillment of the requirements for A K M toward a PhD in the University of Wisconsin Endocrinology and Reproductive Physiology Training Program. A K M was also supported by T32 predoctoral training award (T32HD041921).

\section{Acknowledgements}

The authors would like to thank Gene Ananiev and Song Guo for assistance in the $\mathrm{Ca}^{2+}$ plate reader assays at the University of Wisconsin Small Molecule Screening Facility.

\section{References}

Ampey AC, Boeldt DS, Clemente L, Grummer MA, Yi F, Magness RR \& Bird IM 2019 TNF-alpha inhibits pregnancy-adapted $\mathrm{Ca}(2+)$ signaling in uterine artery endothelial cells. Molecular and Cellular Endocrinology 488 14-24. (https://doi.org/10.1016/j.mce.2019.02.008)

Armant DR, Fritz R, Kilburn BA, Kim YM, Nien JK, Maihle NJ, Romero R $\&$ Leach RE 2015 Reduced expression of the epidermal growth factor signaling system in preeclampsia. Placenta 36 270-278. (https://doi. org/10.1016/j.placenta.2014.12.006)

Bao P, Kodra A, Tomic-Canic M, Golinko MS, Ehrlich HP \& Brem H 2009 The role of vascular endothelial growth factor in wound healing. Journal of Surgical Research 153 347-358. (https://doi.org/10.1016/j. jss.2008.04.023)

Beguin EP, Van Den Eshof BL, Hoogendijk AJ, Nota B, Mertens K, Meijer AB \& Van Den Biggelaar M 2019 Integrated proteomic analysis of tumor necrosis factor alpha and interleukin 1beta-induced endothelial inflammation. Journal of Proteomics 192 89-101. (https:// doi.org/10.1016/j.jprot.2018.08.011)

Boeldt DS \& Bird IM 2017 Vascular adaptation in pregnancy and endothelial dysfunction in preeclampsia. Journal of Endocrinology 232 R27-R44. (https://doi.org/10.1530/JOE-16-0340) 
Boeldt DS, Grummer MA, Magness RR \& Bird IM 2014a Altered VEGFstimulated $\mathrm{Ca} 2+$ signaling in part underlies pregnancy-adapted eNOS activity in UAEC. Journal of Endocrinology 223 1-11. (https://doi. org/10.1530/JOE-14-0252)

Boeldt DS, Hankes AC, Alvarez RE, Khurshid N, Balistreri M, Grummer MA, Yi F \& Bird IM 2014b Pregnancy programming and preeclampsia: identifying a human endothelial model to study pregnancy-adapted endothelial function and endothelial adaptive failure in preeclamptic subjects. Advances in Experimental Medicine and Biology 814 27-47. (https://doi.org/10.1007/978-1-4939-1031-1_4)

Boeldt DS, Grummer MA, Yi F, Magness RR \& Bird IM 2015 Phosphorylation of Ser-279/282 and Tyr-265 positions on Cx43 as possible mediators of VEGF-165 inhibition of pregnancyadapted $\mathrm{Ca} 2+$ burst function in ovine uterine artery endothelial cells. Molecular and Cellular Endocrinology 412 73-84. (https://doi. org/10.1016/j.mce.2015.05.030)

Boeldt DS, Krupp J, Yi FX, Khurshid N, Shah DM \& Bird IM 2017 Positive versus negative effects of VEGF165 on Ca2+ signaling and NO production in human endothelial cells. American Journal of Physiology: Heart and Circulatory Physiology 312 H173-H181. (https://doi. org/10.1152/ajpheart.00924.2015)

Dong W \& Yin L 2014 Expression of lipoxin A4, TNFalpha and IL-1beta in maternal peripheral blood, umbilical cord blood and placenta, and their significance in pre-eclampsia. Hypertension in Pregnancy 33 449-456. (https://doi.org/10.3109/10641955.2014.931419)

Gao F, Sabbineni H, Artham S \& Somanath PR 2017 Modulation of long-term endothelial-barrier integrity is conditional to the cross-talk between Akt and Src signaling. Journal of Cellular Physiology 232 2599-2609. (https://doi.org/10.1002/jcp.25791)

Hammer ES \& Cipolla MJ 2015 Cerebrovascular dysfunction in preeclamptic pregnancies. Current Hypertension Reports 17 64. (https:// doi.org/10.1007/s11906-015-0575-8)

Hohlagschwandtner M, Knofler M, Ploner M, Zeisler H, Joura EA \& Husslein P 2002 Basic fibroblast growth factor and hypertensive disorders in pregnancy. Hypertension in Pregnancy 21 235-241. (https://doi.org/10.1081/PRG-120016790)

Kaplani K, Koutsi S, Armenis V, Skondra FG, Karantzelis N, Champeris Tsaniras S \& Taraviras S 2018 Wound healing related agents: ongoing research and perspectives. Advanced Drug Delivery Reviews 129 242-253. (https://doi.org/10.1016/j.addr.2018.02.007)

Krupp J, Boeldt DS, Yi FX, Grummer MA, Bankowski Anaya HA, Shah DM \& Bird IM 2013 The loss of sustained $\mathrm{Ca}(2+)$ signaling underlies suppressed endothelial nitric oxide production in preeclamptic pregnancies: implications for new therapy. American Journal of Physiology: Heart and Circulatory Physiology 305 H969-H979. (https:// doi.org/10.1152/ajpheart.00250.2013)

Lau SY, Guild SJ, Barrett CJ, Chen Q, Mccowan L, Jordan V \& Chamley LW 2013 Tumor necrosis factor-alpha, interleukin-6, and interleukin-10 levels are altered in preeclampsia: a systematic review and meta-analysis. American Journal of Reproductive Immunology $\mathbf{7 0}$ 412-427. (https://doi.org/10.1111/aji.12138)

Lecarpentier E \& Tsatsaris V 2016 Angiogenic balance (sFlt-1/PlGF) and preeclampsia. Annales d'Endocrinologie 77 97-100. (https://doi. org/10.1016/j.ando.2016.04.007)

Mauro AK, Berdahl DM, Khurshid N, Clemente L, Ampey AC, Shah DM, Bird IM \& Boeldt DS 2020 Conjugated linoleic acid improves endothelial Ca2+ signaling by blocking growth factor and cytokinemediated Cx43 phosphorylation. Molecular and Cellular Endocrinology 510 110814. (https://doi.org/10.1016/j.mce.2020.110814)

Montagnana M, Lippi G, Albiero A, Salvagno GL, Franchi M \& Guidi GC 2008 Serum pro-inflammatory cytokines in physiological and pre-eclamptic pregnancies. Gynecological Endocrinology 24 113-116. (https://doi.org/10.1080/09513590801895575)

Morschauser TJ, Ramadoss J, Koch JM, Yi FX, Lopez GE, Bird IM \& Magness RR 2014 Local effects of pregnancy on connexin proteins that mediate Ca2+-associated uterine endothelial NO synthesis. Hypertension 63 589-594. (https://doi.org/10.1161/ HYPERTENSIONAHA.113.01171)

Nejabati HR, Latifi Z, Ghasemnejad T, Fattahi A \& Nouri M 2017 Placental growth factor (PIGF) as an angiogenic/inflammatory switcher: lesson from early pregnancy losses. Gynecological Endocrinology 33 668-674. (https://doi.org/10.1080/09513590.2017.1318375)

Osol G, Ko NL \& Mandala M 2017 Altered endothelial nitric oxide signaling as a paradigm for maternal vascular maladaptation in preeclampsia. Current Hypertension Reports 19 82. (https://doi. org/10.1007/s11906-017-0774-6)

Pauli JM \& Repke JT 2015 Preeclampsia: short-term and long-term implications. Obstetrics and Gynecology Clinics of North America 42 299-313. (https://doi.org/10.1016/j.ogc.2015.01.007)

Rambaldi MP, Weiner E, Mecacci F, Bar J \& Petraglia F 2019 Immunomodulation and preeclampsia. Best Practice and Research: Clinical Obstetrics and Gynaecology 60 87-96. (https://doi. org/10.1016/j.bpobgyn.2019.06.005)

Sladek SM, Magness RR \& Conrad KP 1997 Nitric oxide and pregnancy. American Journal of Physiology 272 R441-R463. (https://doi. org/10.1152/ajpregu.1997.272.2.R441)

Solan JL \& Lampe PD 2014 Specific Cx43 phosphorylation events regulate gap junction turnover in vivo. FEBS Letters 588 1423-1429. (https:// doi.org/10.1016/j.febslet.2014.01.049)

Street ME, Seghini P, Fieni S, Ziveri MA, Volta C, Martorana D, Viani I, Gramellini D \& Bernasconi S 2006 Changes in interleukin-6 and IGF system and their relationships in placenta and cord blood in newborns with fetal growth restriction compared with controls. European Journal of Endocrinology 155 567-574. (https://doi.org/10.1530/eje.1.02251)

Szarka A, Rigó J, Lázár L, Beko G \& Molvarec A 2010 Circulating cytokines, chemokines and adhesion molecules in normal pregnancy and preeclampsia determined by multiplex suspension array. $B M C$ Immunology 11 59. (https://doi.org/10.1186/1471-2172-11-59)

Umapathy A, Chamley LW \& James JL 2020 Reconciling the distinct roles of angiogenic/anti-angiogenic factors in the placenta and maternal circulation of normal and pathological pregnancies. Angiogenesis $\mathbf{2 3}$ 105-117. (https://doi.org/10.1007/s10456-019-09694-w)

Xie C, Yao MZ, Liu JB \& Xiong LK 2011 A meta-analysis of tumor necrosis factor-alpha, interleukin-6, and interleukin-10 in preeclampsia. Cytokine 56 550-559. (https://doi.org/10.1016/j.cyto.2011.09.021)

Yi FX, Boeldt DS, Gifford SM, Sullivan JA, Grummer MA, Magness RR \& Bird IM 2010 Pregnancy enhances sustained Ca2+ bursts and endothelial nitric oxide synthase activation in ovine uterine artery endothelial cells through increased connexin 43 function. Biology of Reproduction 82 66-75. (https://doi.org/10.1095/ biolreprod.109.078253)

Yi FX, Boeldt DS, Magness RR \& Bird IM 2011 [Ca2+]i signaling vs. eNOS expression as determinants of NO output in uterine artery endothelium: relative roles in pregnancy adaptation and reversal by VEGF165. American Journal of Physiology: Heart and Circulatory Physiology 300 H1182-H1193. (https://doi.org/10.1152/ ajpheart.01108.2010)

Zhang Y, Gu Y, Li H, Lucas MJ \& Wang Y 2003 Increased endothelial monolayer permeability is induced by serum from women with preeclampsia but not by serum from women with normal pregnancy or that are not pregnant. Hypertension in Pregnancy 22 99-108. (https://doi.org/10.1081/PRG-120017008)

Received in final form 3 November 2020

Accepted 25 November 2020

Accepted Manuscript published online 1 December 2020 https://joe.bioscientifica.com https://doi.org/10.1530/JOE-20-0397 (c) 2021 Society for Endocrinology Published by Bioscientifica Ltd. Printed in Great Britain 